\title{
Nonlinear Budó Model for Dielectric Relaxation: Comparison with New Experimental Data
}

\section{F. Marchesoni}

Abteilung für Theoretische Physik, Universität Ulm, Federal Republic of Germany

\section{J.K. Vij and W.T. Coffey}

Department of Microelectronics and Electrical Engineering, Trinity College, Dublin, Ireland

Z. Phys. B - Condensed Matter 61, 357-366 (1985)

Confused notation makes it difficult to follow our analysis. In particular,

(i) in Eqs. (2.10) (2.14), $\gamma$ is to be replaced with $4 \gamma$;

(ii) Eq. (2.12) should read

$U_{\omega}(t)=\mathrm{e}^{-\beta t / 2}\left[\cos \Omega t+\frac{\beta}{2 \Omega} \sin \Omega t\right]$.

As a consequence of $(i)$, the fit in Fig. 3 is also affected - see Chem. Phys. Lett. 129, 375 (1986) for a revised version.
F. Marchesoni

Abteilung für Theoretische Physik

Universität Ulm

Oberer Eselsberg

D-7900 Ulm

Federal Republic of Germany

J.K. Vij, W.T. Coffey

Department of Microelectronics

and Electrical Engineering

Trinity College

Dublin

Ireland 